\title{
Optimal Allocation of Renewable Distributed Generations Using Sensitivity Analysis and PSO
}

\author{
$1^{\text {st }}$ Sugiarto $^{1}, 2^{\text {nd }}$ Oni Yuliani ${ }^{2}$ \\ \{sugiarto.kadiman@itny.ac.id ${ }^{1}$, onisudaryono@gmail.com²
}

Study Program of Electrical Engineering, Institut Teknologi Nasional Yogyakarta, Indonesia ${ }^{1,2}$

\begin{abstract}
A growing demand for electricity, along with a scarcity of available producing capacity, has fueled the growth of Renewable Distributed Generation (RDG), which includes wind, solar, and hydroelectric sources of energy. Abstract: The location of DG sources has a significant effect on the amount of system losses that occur in the distribution network. This study discusses the identification of the most suitable placement for the IEEE 30 Bus Test System to reduce power loss while simultaneously improving voltage deviation. It is necessary to utilize Sensitivity Analysis to determine the placement of DGs in the network, while Particle Swarm Optimization is used as the optimization method to determine the size of DGs in the network in order to minimize the power losses of the system. The findings demonstrate that the installation of three DGs is beneficial in minimizing power loss and voltage variation.
\end{abstract}

Keywords: Sensitivity, distribution network, Distributed Generation

\section{Introduction}

Because of the limited availability of fossil fuel supplies, alternative alternatives to conventional big power plants have gained significant attention in recent years as a means of meeting the anticipated increase in energy demand in the future. When compared to huge fossil-fuel-based power plants, the sizes of renewable-energy-based electricity producers would be very tiny. They are strictly speaking only appropriate for installation on lower voltage grid systems, close to load centers [1]. DG may be used in a variety of applications, including industrial, commercial, and residential. To compete with conventional big generators in certain places, DG makes use of cutting-edge contemporary technology that is both efficient and dependable. As a result of Indonesia's geographic position inside the ring of fire and volcanic line, it possesses a large amount of geothermal potential. Sumatra, Java, Bali, Nusa Tenggara, and Sulawesi are just a few of the islands where this site may be found, with 312 locations scattered throughout the country. Geothermal energy potential is estimated to be about $29 \mathrm{GW}$ in capacity. This Renewable distributed generation (DG) systems may provide both active and reactive electricity to the load center [3]. The difficulty, however, is the location of the facility and the size of the facility. It is possible that the installation of DG units in less than ideal locations and with less than optimal size may result in an increase in system losses and damage to the voltage state. The technical component of renewable DG may be used to evaluate its performance. One of the most significant factors in almost all DG assessments is the influence on power quality, such as energy losses in [4] and sufficient power in [5]. However, this factor is insufficient for complete evaluations. Despite its promise, connecting renewable distributed generation (DG) to a power grid is not a straightforward "plug and play" issue. When several kinds of renewable DGs are taken into consideration, the issue becomes more complicated. 
A multi-objective optimization problem with several objectives may be used to describe the difficulties associated with renewable DG deployment. Power losses, voltage state, fuel cost, and investment cost are all considered objective functions in [6]-[7], and they are all improved simultaneously using a specific optimization method described in [6]. The multi-objective optimization approach has the potential to provide a number of interesting trade-offs. The techno model, which incorporates both power losses and voltage state features that have been optimized concurrently [8]-[9]-[10], has been one of the most prominent multi-objective functions in recent years. When the designer's primacy is taken into consideration, the chosen optimizing technique may be decided successfully without sacrificing generality. Renewable distributed generation (DG) units in a grid system may be represented as a non-deterministic polynomial optimization problem, as illustrated in Figure 1. Heuristic methods are more successful in determining the solution to such complicated issues [11]. However, despite the fact that the technique is successful in terms of site selection, it requires more computing work. Every bus is equipped with a computer that calculates the optimum value of DG for minimizing system losses. The associated system losses are computed and compared for each bus in turn, using the estimated DG size for each bus. This allows us to determine the most suitable placement. Furthermore, the heuristic search entails a thorough search for all potential sites, which may not be relevant to more than one DG because to the lengthy search involved. The intelligent searchbased population techniques have mostly been investigated for the purpose of solving multiobjective problems $[12,13]$. Particle Swarm Optimization, often known as PSO, is a technique that may be used to discover solutions that are more quickly convergence. The benefits of PSO are thus straightforward to implement, with just a few parameters to tweak [13]. PSO-based method that takes the number and location of DGs as input has been developed to find the optimum size of DG in order to reduce actual power losses in grid systems. The optimal size of DG is determined in order to minimize real power losses in grid systems. The benefits of relieving PSO of the responsibility for determining the locations of DGs include better convergence characteristics and reduced calculation time. Tests are carried out using the IEEE 30 Bus Test System to validate the suggested algorithm-based method.

\section{Methods of Investigation}

Most of the time, the reduction in actual power loss results in increased reflection for the utilities as a result of the reduction in proficiency throughout the energy distribution process. The decrease of power loss via properly positioned Renewable DGs along the grid feeder may be very beneficial if the goal of the planning is to minimize losses while simultaneously improving network performance. On the contrary, the grid system is obliged to maintain the voltage level of each user bus within the limits set by the regulatory body in place. In order to ensure that voltage profiles in grid systems are appropriate, the usual voltage has been developed to provide criteria for use. Furthermore, reactive power loss seems to be no less significant than active power loss since it reduces the possibility of providing actual power to consumers via transmission lines. Following that, it is necessary to ensure that the flow of reactive power in the system is well-preserved at the desired voltage level. Power system real and reactive power flows in a line connecting two buses, power system real and reactive power losses in a line connecting two buses, power system real and reactive power losses in a line connecting two buses, and may be characterized as follows:

[14]: 


$$
P_{i j}=V_{i} V_{j} Y_{i j} \cos \left(\theta_{i j}+\delta_{i j}\right)-V_{i}^{2} Y_{i j} \cos \theta_{i j} \quad Q_{i j}=V_{i} V_{j} Y_{i j} \sin \left(\theta_{i j}+\delta_{i j}\right)-V_{i}^{2} Y_{i j} \sin \theta_{i j}-\frac{V_{i}^{2} Y_{s h}}{2}
$$

(1)

$$
P_{L(i j)}=g_{i j}\left(V_{i}^{2}+V_{j}^{2}-2 V_{i} V_{j} \cos \delta_{i j}\right) \quad Q_{L(i j)}=-b_{i j}^{s h}\left(V_{i}^{2}+V_{j}^{2}\right)-b_{i j}\left(V_{i}^{2}+V_{j}^{2}-2 V_{i} V_{j} \cos \delta_{i j}\right)
$$

(2)

The analysis of sensitivity is used to circumvent recalculation of the power flow solution. The used parameters is the power transfer distribution factors and are defined as the changes in the line power flows due to a change in power injection at a specific bus. The sensitivities is to be calculated by examining the Jacobian matrix at a particular solution of the network [15].

By definition power sensitivity is the alteration in real power flow $\left(\Delta P_{i j}\right)$ and reactive power flow $\left(\Delta Q_{i j}\right)$ in a transmission line- $k$ connected between bus- $i$ and bus- $j$ due to unit change in the power injection $\left(\Delta P_{n}\right)$ and $\left(\Delta Q_{n}\right)$, respectively, at any bus- $n$. Mathematically, the power flow sensitivity can be written as $\frac{\Delta P_{i j}}{\Delta P_{n}}$ and $\frac{\Delta Q_{i j}}{\Delta Q}[16]$. Expending Taylor series approximation, change in line flows can be written by ignoring second and higher order terms as

$$
\Delta P_{i j}=\frac{\partial P_{i j}}{\partial \delta_{i}} \Delta \delta_{i}+\frac{\partial P_{i j}}{\partial \delta_{j}} \Delta \delta_{j}+\frac{\partial P_{i j}}{\partial V_{i}} \Delta V_{i}+\frac{\partial P_{i j}}{\partial V_{j}} \Delta V_{j} \quad \Delta Q_{i j}=\frac{\partial Q_{i j}}{\partial \delta_{i}} \Delta \delta_{i}+\frac{\partial Q_{i j}}{\partial \delta_{j}} \Delta \delta_{j}+\frac{\partial Q_{i j}}{\partial V_{i}} \Delta V_{i}+
$$

$\frac{\partial Q_{i j}}{\partial V_{j}} \Delta V_{j}$

From these equations power flow, sensitivity factor can be calculated which is giving by

$$
\left[\begin{array}{l}
\frac{\partial P_{i j}}{\partial P_{n}} \\
\frac{\partial P_{i j}}{\partial Q_{n}}
\end{array}\right]=\left[\begin{array}{l}
F_{P-P} \\
F_{P-Q}
\end{array}\right]=\left[J^{T}\right]^{-1}\left[\begin{array}{c}
\frac{\partial P_{i j}}{\partial \delta} \\
\frac{\partial P_{i j}}{\partial V}
\end{array}\right] \quad\left[\begin{array}{l}
\frac{\partial Q_{i j}}{\partial P_{n}} \\
\frac{\partial Q_{i j}}{\partial Q_{n}}
\end{array}\right]=\left[\begin{array}{l}
F_{Q-P} \\
F_{Q-Q}
\end{array}\right]=\left[J^{T}\right]^{-1}\left[\begin{array}{c}
\frac{\partial Q_{i j}}{\partial \delta} \\
\frac{\partial Q_{i j}}{\partial V}
\end{array}\right]
$$

While power loss sensitivity factor can be assessed using

$$
\left[\begin{array}{c}
\frac{\partial P_{L(i j)}}{\partial P_{n}} \\
\frac{\partial P_{L(i j)}}{\partial Q_{n}}
\end{array}\right]=\left[\begin{array}{c}
S_{P-P} \\
S_{P-Q}
\end{array}\right]=\left[J^{T}\right]^{-1}\left[\begin{array}{c}
\frac{\partial P_{L(i j)}}{\partial \delta} \\
\frac{\partial P_{i j}}{\partial V}
\end{array}\right] \quad\left[\begin{array}{c}
\frac{\partial Q_{L(i j)}}{\partial P_{n}} \\
\frac{\partial Q_{L(i j)}}{\partial Q_{n}}
\end{array}\right]=\left[\begin{array}{l}
S_{Q-P} \\
S_{Q-Q}
\end{array}\right]=\left[J^{T}\right]^{-1}\left[\begin{array}{c}
\frac{\partial Q_{L(i j)}}{\partial \delta} \\
\frac{\partial Q_{i j}}{\partial V}
\end{array}\right]
$$

(5)

Both power flows and power losses can be incorporated into the form of factor of combined sensitivity (CSF) as follows:

$$
C S F_{i}=\left(F_{P-P_{i}} \times F_{Q-P_{i}}\right)+\left(F_{P-Q_{i}} \times F_{Q-Q_{i}}\right)+\left(S_{P-P_{i}} \times S_{Q-P_{i}}\right)+\left(S_{P-Q_{i}} \times S_{Q-Q_{i}}\right)
$$




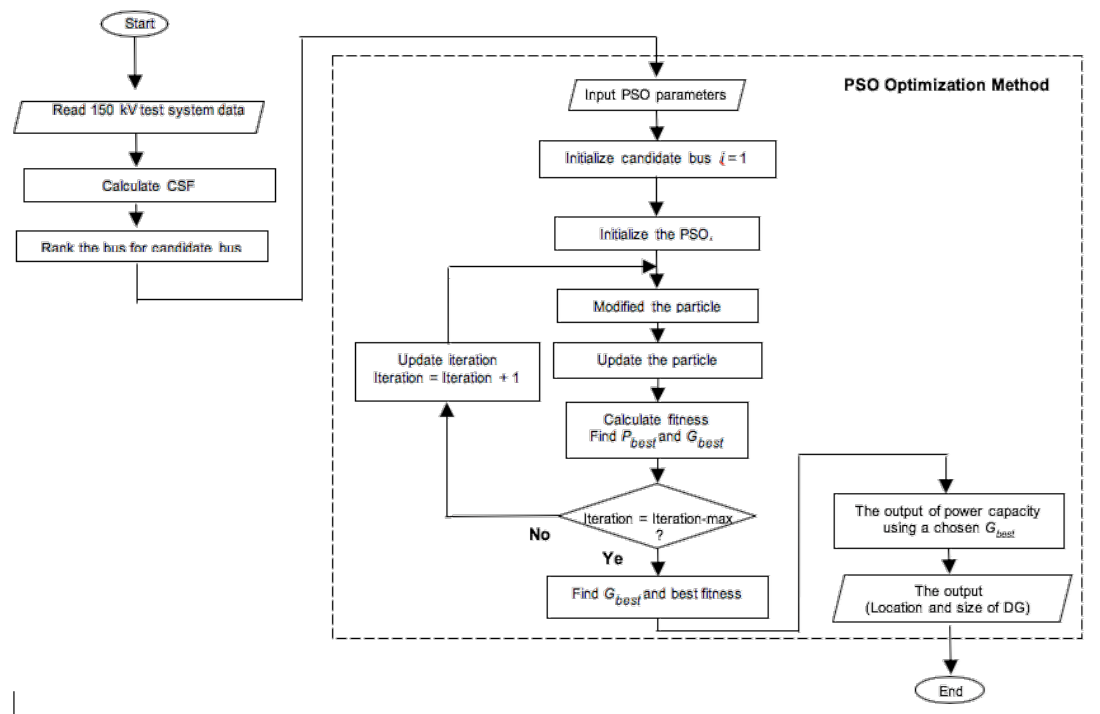

Fig. 1. Flowchart of proposed algorithm

The mentioned multi-objective function is minimized with attention paid to many operational restrictions, such as the real and reactive power generation limits, the voltage limit, and the DG's real and reactive power production limits, in order to meet the electrical requirements of the grid system. The following is the performance calculation of the suggested multi-objective function (MOF) for allocating renewable distributed generation (DG) in grid systems:

$$
M O F=w_{1} P L R I+w_{2} Q L R I+w_{2} V P I \quad\left|w_{1}\right|+\left|w_{2}\right|+\left|w_{3}\right|=1
$$

Real power loss reduction index (PLRI), reactive power loss reduction index (QLRI), and voltage profile improvement index (PVII) are all measures of power loss reduction. The suggested PSO-based approach for optimum placement of renewable DG in the distribution system is shown in Figure 1 as a flowchart.

\section{Results and Discussion}

The single line diagram of IEEE 30 Bus test system is shown in Fig. 2. 


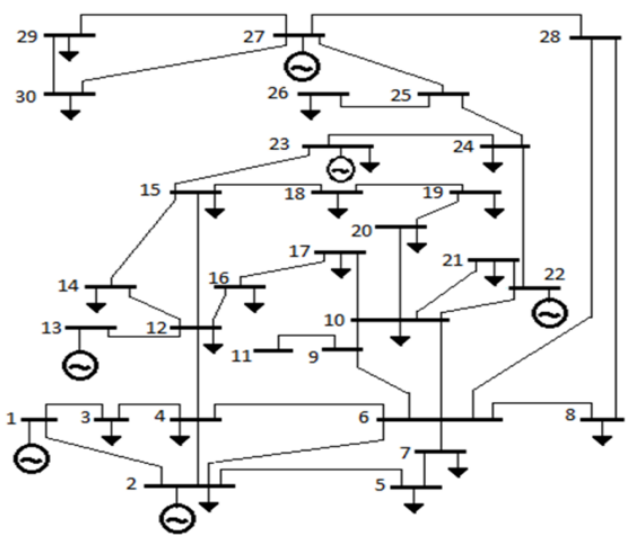

Fig. 2. Single line diagram of Test System [17]

The CSF all buses of IEEE 30 Bus Test System were calculated based on Equation 7. Candidate buses were selected by choosing CSF values more than 0.8 . The optimal placement of the Renewable DGs could be able to choose by carefully observing at all the candidate buses, shown in Table 1.

Table 3: Results for CSF, Fitness, and optimal DG sizes (Based $120 \mathrm{MW}$ ) for candidate buses

\begin{tabular}{|c|c|c|c|}
\hline Candidate Bus & CSF & Fitness & $\begin{array}{c}\text { DG size } \\
\text { (MW) }\end{array}$ \\
\hline 10 & 0,8808 & 0,9164 & 110,680 \\
11 & 0,9266 & 0,9188 & 116,445 \\
15 & 0,8377 & 0,9182 & 114,582 \\
17 & 0,8755 & 0,9151 & 107,347 \\
18 & 1,0218 & 0,9188 & 115,198 \\
19 & 1,0945 & 0,9206 & 119,289 \\
20 & 1,0631 & 0,9203 & 118,929 \\
21 & 0,9973 & 0,9093 & 92,237 \\
22 & 1,0554 & 0,9194 & 117,708 \\
23 & 0,9911 & 0,9204 & 118,984 \\
24 & 1,0350 & 0,9205 & 119,112 \\
25 & 0,8770 & 0,9155 & 107,875 \\
26 & 1,0086 & 0,9195 & 119,082 \\
30 & 0,8160 & 0,9209 & 118,938 \\
\hline
\end{tabular}

Table 4. Comparison of Results using DG

\begin{tabular}{|c|c|c|c|c|}
\hline $\begin{array}{c}\text { Bus } \\
\text { No. }\end{array}$ & $\begin{array}{c}\text { DG size } \\
\text { (MW) }\end{array}$ & $\begin{array}{c}\text { Power Losses } \\
\text { (MW) }\end{array}$ & $\begin{array}{c}\text { Power Loss } \\
\text { Reduction } \\
\text { (MW) }\end{array}$ & $\begin{array}{c}\text { Percentage Power } \\
\text { Loss Reduction (\%) }\end{array}$ \\
\hline 10 & 110,680 & 136,69 & 38,59 & 22,02 \\
19 & 119,289 & & & \\
\cline { 2 - 4 } & & &
\end{tabular}


The findings for actual power losses and voltage levels were obtained via the use of NewtonRaphson load flow. The inclusion of DGs has no impact on the departure of voltage levels outside of permissible limits [13], as previously stated. Evidently, all of the bus voltages are in the region of $1.0 \mathrm{pu}$ to $1.1 \mathrm{pu}$, which is consistent with the data. Table 4 demonstrates that renewable distributed generation (DG) contributed to a substantial reduction in actual power loss. The percentage decrease in actual power loss is $38,59 \mathrm{MW}$, or 22,02 percent, according to the data.

\section{Conclusion Remarks}

It has been successfully applied the PSO-based method for system loss reduction and voltage profile enhancement in the IEEE 30 Bus Test System by optimizing the placement and size of renewable DG units, such as geothermal power plants. The combined sensitivity factors were developed and used successfully in order to reduce the number of candidates placed in Renewable DGs. When utilizing this test system, this optimization technique resulted in a substantial loss reduction when compared to other methods. The percentage decrease in actual power loss was $38,59 \mathrm{MW}$, or 22,02 percent, according to the results. When it comes to bus voltage, the lowest voltage level has been increased from $0.9953 \mathrm{pu}$ to $1.0012 \mathrm{pu}$, while the maximum voltage level has remained at $1.0710 \mathrm{pu}$.

\section{Acknowledgments.}

The authors would like to thank to Rector of ITNY and Head of LPPM ITNY for subsidy this project and Head of Technic Department ITNY for providing necessity services.

\section{References}

[12] Momoh JA, and Reddy SS 2014 Review of Optimization Techniques for Renewable Energy Resources IEEE Transaction on Power System vol. 14 issue 1 pp 95-114

[2] Ackermann T, Andersson G, and Soder L 2001 Distributed Generation: a Definition Electric Power Systems Research vol. 57 pp195-204

[3] Pambudi NA 2017 Geothermal power generation in Indonesia, a country within the ring of fire: Current status, future development and policy Renewable and Sustainable Energy Reviews vol. 8 part 2 pp 2893-2901

[4] Karajgi SB, Udaykumar RY, and Kamalapur GD 2012 Modeling of Power Generation using Municipal Solid Waste in India. International Journal of Electrical and Computer Engineering (IJECE) vol. 2 no. 2 pp 197-202

[5] Singh SK, and Goswami SK 2010 Optimum Allocation of Distributed Generations Based on Nodal Pricing for Profit, Loss Reduction, and Voltage Improvement Including Voltage Rise Issue. International Journal of Electrical Power \& Energy Systems vol. 32 no. 6 pp 637-644

[6] Hong YY, and Ho SY 2005 Determination of Network Configuration Considering Multi-objective in Distribution System Using Genetic Algorithm IEEE Transaction on Power System vol. 20 no. 2 pp 1062-1069

[7] Sharaf AM, and El-Gamal AAA 2009 A Multi Objective Multi-Stage Particle Swarm Optimization (MOPO) Search Scheme for Power Quality and Loss Reduction on Radial Distribution System Proceeding of International Conference on Renewable Energies and Power Quality (ICEREQ'09) 
[8] Mohammadi MTA, and Faramarzi M 2012 PSO Algorithm for Sitting and Sizing of Distributed Generation to Improve Voltage Profile and Decreasing Power Losses Proceeding of 17th Conference on Electrical Power Distribution Network (EPDC)

[9] Musa H, and Adamu SS 2012 PSO based DG sizing for Improvement of Voltage Stability Index in Radial Distribution Systems Proceedings of the IASTED International Conference Power and Energy Systems and Applications pp 175-180.

[10] El-Zonkoly AM 2011 Optimal Placement of Multi-distributed Generation Units Including Different Load Models Using Particle Swarm Optimisation. IEEE Transaction on Generation, Transmission, and Distribution vol. 5 issue 7 pp 760-771.

[11] Lee KY, and El-Sharkawi MA 2008 Modern Heuristic Optimisation Techniques: Theory and Applications to Power Systems (New Jersey: John Wiley \& Sons, Inc.) pp 586

[12] Shahinzadeh H, Nasr-Azadani SH, and Jannesari N 2014 Applications of Particle Swarm Optimization Algorithm to Solving the Economic Load Dispatch of Units in Power Systems with Valve-Point Effects International Journal of Electrical and Computer Engineering vol. 4 no. 6 pp 858-867.

[13] Nasir MNM, Shahrin NM, Sulaima MF, Jali, MF, and Baharon, MF 2014 Optimum Network Reconfiguration and DGs Sizing With Allocation Simultaneously by Using Particle Swarm Optimization (PSO) International Journal of Engineering and Technology vol. 6 no. 2 pp 773-780

[14] Charles JK, and Odero NA 2013 A Combined Sensitivity Factor based GA-IPSO Approach for System Loss Reduction and Voltage Profile Enhancement International Journal of Innovative Research in Engineering \& Science vol. 12 issue 2

[15] Ahmadi H, Martí JR, and Alsubaie A 2015 Sensitivity Factors for Distribution Systems IEEE Proceeding on Power and Energy Society General Meeting

[16] Sai Krishna Kanth D, Padma Lalita M, and Suresh Babu P 2016 Siting \& Sizing of DG for Power Loss \& THD Reduction, Voltage Improvement Using PSO \& Sensitivity Analysis International Journal of Engineering Research and Development vol. 9 issue 6 pp 01-07

[17] IEEE Distribution Planning Working Group Report 1991 Radial Distribution Test Feeders IEEE Transactions on Power Systems vol. 6 no. 3 pp 975-985. 